\title{
On numerical earthquake prediction
}

\author{
Yaolin Shi $\cdot$ Bei Zhang $\cdot$ Siqi Zhang $\cdot$ \\ Huai Zhang
}

Received: 17 September 2013/ Accepted: 19 March 2014/Published online: 6 May 2014

(C) The Seismological Society of China, Institute of Geophysics, China Earthquake Administration and Springer-Verlag Berlin Heidelberg 2014

\begin{abstract}
Can earthquakes be predicted? How should people overcome the difficulties encountered in the study of earthquake prediction? This issue can take inspiration from the experiences of weather forecast. Although weather forecasting took a period of about half a century to advance from empirical to numerical forecast, it has achieved significant success. A consensus has been reached among the Chinese seismological community that earthquake prediction must also develop from empirical forecasting to physical prediction. However, it is seldom mentioned that physical prediction is characterized by quantitatively numerical predictions based on physical laws. This article discusses five key components for numerical earthquake prediction and their current status. We conclude that numerical earthquake prediction should now be put on the planning agenda and its roadmap designed, seismic stations should be deployed and observations made according to the needs of numerical prediction, and theoretical research should be carried out.
\end{abstract}

Keywords Earthquake prediction - Geodynamics · Numerical method $\cdot$ Nonlinear dynamics

\section{A brief review on earthquake prediction}

People suffer a lot from natural hazards. How to predict and prevent them has been an important issue for a long time. In 1884, an article about weather forecast

Y. Shi $(\bowtie) \cdot$ B. Zhang $\cdot$ S. Zhang $\cdot$ H. Zhang

Laboratory of Computational Geodynamics of Chinese Academy

of Sciences, University of Chinese Academy of Sciences,

Beijing 100049, China

e-mail: shiyl@gucas.ac.cn
(Anonymous 1884) published on Science which pointed out that "The methods by which weather forecasts are made are based almost wholly upon facts of observation rather than upon established deductions of science. This is unavoidable, because atmospheric movements are very complicated, and because the science of meteorology is not yet sufficiently advanced to satisfactorily explain them in the detail necessary for successful forecasting”. In 1922, Richardson proposed the idea that weather forecast can be made numerically by solving a set of equations (Richardson 1922). Although he failed to put the idea into successful practice due to lack of computing ability at that time, his paper "Weather Prediction by Numerical Process" still made him the pioneer on numerical weather forecast. Media expected weather forecast could be done in a computing factory where people compute together just as musicians play together in symphony orchestra (Fig. 1). After hard working of many scientists, in 1950, Charney implemented the first numerical weather forecast using ENIAC electronic computer. In the 1970s and 1980s, numerical weather forecast became a practical technique. Now, it is the major technique to predict weather change in developed countries.

In 1909, American geologist Gilbert also published an article in Science titled "Earthquake Forecasts Introduction" (Gilbert 1909). In the article, he said "There was a time when the weather belonged to the gods. Storms and drought were inflicted on man in punishment or for vengeance, man strove to avert them by sacrifice or prayer, and the priest was his intercessor. Now the weather belongs to nature, and the priestly robe has fallen on the Weather Bureau. Man's new agent, however, is not an intercessor; he does nothing to placate; he makes no attempt to control the course of nature; but inspired by science he foretells the coming changes so that his lay client may take warning and 


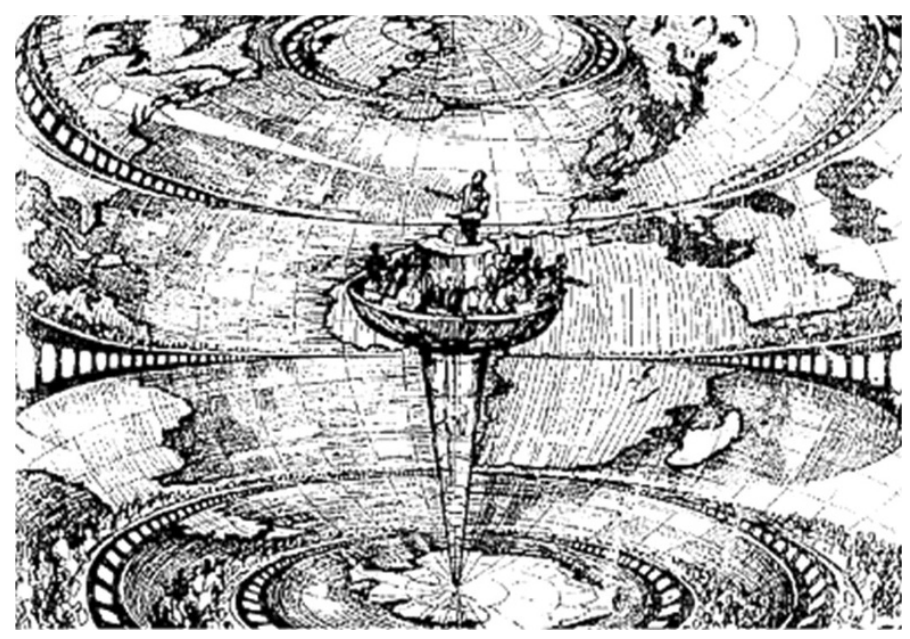

Fig. 1 An imaginary worldwide computational factory based on Lewis Fry Richardson's ideal

be prepared. The crops are harvested before the rain, the herds escape from the lowland before the flood, the ships reach harbor before the gale; and man chants a hymn of praise to science. There was a time when the earthquake was equally enveloped in mystery, and was forecast in the enigmatic phrases of the astrologer and oracle; and now that it too has passed from the shadow of the occult to the light of knowledge, the people of the civilized Earth-the lay clients of the seismologist-would be glad to know whether the time has yet come for a scientific forecast of the impending tremor". Unfortunately, although lots of research was done on the issue, the progress of earthquake prediction is far behind weather forecast. Unlike weather forecast which has became a practical technique already, earthquake prediction was thought impossible in a long time. For example, two famous seismologists Wood and Gutenberg said in 1935 in Science "Every once in a while, as recently, the claim that earthquakes can be predicted is brought to public attention in the press or in other ways. Some of the claimants are obviously not competent; others proceed along rational lines but without due regard to the difficulties involved. Some may be publicity seekers; others are undoubtedly sincere." They also proposed the three major elements of earthquake prediction, "Unless the region or district, not too great in area, and the exact or closely approximate time, and the shock magnitude are stated - any earthquake prediction stands a good chance of apparent verification because of the great number of shocks which occur in all seismic regions in a given period. If a vague prediction is made and news of a shock is sought to check it, then a vague verification is more than likely to be obtained." (Wood and Gutenberg 1935).

The research on earthquake prediction did not run smoothly. After the 1960 Chile $M_{\mathrm{w}} 9.5$ earthquake and 1964 Alaska $M_{\mathrm{w}} 9.2$ earthquake, during $1960 \mathrm{~s}$ and $1970 \mathrm{~s}$, scientists in the US, Japan, and the former Soviet Union surged to research earthquake short-time prediction (Press and Brace 1966; Haciwara and Rikitakk 1967). In 1966, American geophysicists Press and Brace wrote down "A few years ago the subject of earthquake prediction fell under the purview of astrologers, misguided amateurs, publicity seekers, and religious sects with doomsday philosophies. No wonder that the occasional scientist who ventured an opinion on the subject did so with trepidation and then with conservatism lest, he be disowned by his colleagues. The situation has changed dramatically in the last 3 years. Three of Japan's foremost earth scientists proposed a program of research and concluded that 'after ten years the amount of data should be fairly adequate for earthquake prediction.' ... In the United States an Ad Hoc Panel on Earthquake Prediction was appointed by the Office of Science and Technology (OST). After some 15 months of deliberation the panel saw enough possibilities to justify a 10-year program of research, which they proposed to Donald Hornig, the director of OST. Their report is now under consideration by several government agencies" (Press and Brace 1966). When rocks are about to broken, the amount of micro-cracks would increase rapidly, as a result, dilation happens, water flows and seismic wave velocity changes. Based on these phenomena, American Scientists thought they found reasonable earthquake precursors (Scholz et al. 1973). In Japan, in 1965, an earthquake prediction program was started as a national project. In 1978, a program for constant monitoring and assessment was formally inaugurated with the goal of forecasting the major earthquake that is expected to occur in the near future in the Tokai district of central Honshu Island (Mogi 1986).

China is a country which was stricken by lots of earthquakes, and Chinese people made a lot of efforts on earthquake prediction. In 1953, Chinese Academy of Sciences established an Earthquake Work Committee, headed 
by Siguang $\mathrm{Li}$ as the director and Kezhen Zhu as the vice director. The 1st seismic intensity zoning map of China published in 1956 based on the analyses of historical earthquakes and geological structures (Lee 1957). In 1956, a famous Chinese geophysicist Cheng-Yi Fu proposed a plan on earthquake prediction including how to carry it out in a scientific way. In 1963, Fu published a paper about earthquake prediction in Chinese Science Bulletin (Fu 1963). After the 1962 Xinfengjiang $M_{\mathrm{s}} 6.2$ earthquake and the 1966 Xingtai $M_{\mathrm{s}} 6.8$ and $M_{\mathrm{s}} 7.2$ earthquakes, earthquake prediction was proposed to the agenda. Especially after the Xingtai earthquake which caused more than 8,000 deaths, late Premier Zhou inspected the disaster area several times and demanded scientist to research on earthquake prediction. It then became an important issue of Earth science in China. China became the only country that regard earthquake prediction as a daily routine, and Chinese Earthquake Administration was established for this purpose. In 1971, Fu published an article in Earthquake Frontier, in which he pointed out "the direct signal could be used for prediction is precursor, to find effective precursor should always be an important way to predict earthquake" (Fu 1971). He listed a few candidate precursors, including foreshock/micro earthquake, earth inclination/crustal deformation, geomagnetic field, seismic wave velocity, ground water level, ground temperature, terrestrial electricity, animal behavior, lunar phase, and climate, etc. He also pointed out that "earthquake prediction is a very difficult problem". In 1975, the Haicheng $M_{\mathrm{s}} 7.3$ earthquake was a practical success; there was indeed issuance of imminent warning across a large region, although no official short-term prediction was issued (Wang et al. 2006). This gave credit to all the scientists who made efforts to the research on earthquake prediction since 1966, the beginning of earthquake prediction in China.

But the difficulties are far beyond expectation. In 1976, scientists failed to predict the Tangshan $M_{\mathrm{s}} 7.8$ earthquake which took more than 240,000 lives (State Seismological Bureau of China, 1982). Most earthquakes striking the United States west coast took place along the San Andres fault which is the boundary of Pacific plate and North America plate. Especially around Parkfield, an obvious pattern was observed, that is a $M 6$ earthquake happened about every 22 years, the pattern repeated 6 times since 1857 and the last event took place in 1966. So scientists decided to do some experiment on earthquake prediction in Parkfield (Bakun and McEvilly 1979). In 1985, they made the prediction that an $M 6$ earthquake would be happen within 5 years. In 1992, a short-term prediction announced that an M4 earthquake would happen in $72 \mathrm{~h}$. But, the event did not come until 2004 (Bakun et al. 2005), and it missed the experiment which was stopped in 1993 (Kerr 1993). In 1989, an $M_{\mathrm{w}} 6.9$ earthquake strike Loma Prieta located $100 \mathrm{~km}$ south to San Francisco. In 1992, an $M_{\mathrm{w}} 7.3$ earthquake strikes Landers which located $200 \mathrm{~km}$ south to Los Angeles. No precursor was observed before the two events. Because of these failures, some people kept a negative attitude to earthquake prediction. In 1997, Geller, etc., published an article titled "Earthquake cannot be predicted" in Science (Geller et al. 1997). He said that "Earthquake prediction research has been conducted for over 100 years with no obvious successes. Claims of breakthroughs have failed to withstand scrutiny. Extensive searches have failed to find reliable precursors. Theoretical work suggests that faulting is a non-linear process which is highly sensitive to immeasurably fine details of the state of the Earth in a large volume, not just in the immediate vicinity of the hypocenter. Any small earthquake thus has some probability of cascading into a large event. Reliable issuing of alarms of imminent large earthquakes appears to be effectively impossible."(Geller 1997).

However, researches on earthquake prediction were not stopped. In response to Geller et al. (1997) paper, Wyss (1997) argued against Geller et al. in his letter "Cannot earthquake be predicted?" In practice, scientists have kept on making earthquake prediction in the USA, Japan, and Europe (e.g., Keilis-Borok 2002; Chadha et al. 2003; Uyeda and Kamogawa 2008; Marzocchi and Lombardi 2009). Davis et al. (2012) pointed out that M8 method has been tested worldwide for more than 25 years, and the results show at least a $70 \%$ success rate, a 2001 mid-term prediction provided a chance for the Tohuko $M_{\mathrm{w}} 9.0$ earthquake disaster preparedness but the opportunity was unfortunately missed. Uyeda et al. (2009) discussed roles of the non-seismic precursors. New precursors have been explored, and multi-parameter method is sought (Kalenda et al. 2013). Chinese scientist did not give up the research as well. There were claims of successful predictions of a few earthquakes (e.g. Zhang et al. 1999). However, overall the research on this subject has been kept on for half century but little progress was made. Scientists failed to predict the 2008 Wenchuan $M_{\mathrm{w}} 7.9$ earthquake and the $2011 M_{\mathrm{w}} 9.0$ Tohoku earthquake. Several papers have been published to discuss scientific problems of earthquake prediction in China (Chen 2009; Chen and Wang 2010; Bormann 2011). We would like to make a prospective view on earthquake prediction in this article.

\section{Concepts related to earthquake prediction}

Before going any further, let us discuss whether or not earthquakes could be predicted. There is a famous empirical law in seismology called the Gutenberg-Richter law: $\log N=a-b M$ (Gutenberg and Richter 1954), which relates the number $N$ which count the events 
greater than magnitude M. Bak suggested the famous sand-pile model (Bak et al. 1987; Bak and Tang 1989) which they believe to be able to simulate how earthquakes happen. The simulation took place like this, drop sand grains randomly into square-divided cells standing for stress accumulation. When the amount of sand grains in a cell reached a preset number ( 4 in this case), the cell collapses that means removing four sand grains from it to simulate stress drop in earthquake. At the same time, add one sand grain into each of the four neighboring cells to simulate stress increase in the vicinity. Collapse of one single cell stands for a small earthquake, while collapse of a bundle of cells stands for a great earthquake. Running this model can produce the Gutenberg-Richter law. The system develops into a highly sensitive unstable state named self-organized critical state (SOC). If one randomly drops a sand grain into the system in SOC state, the result is unpredictable. Barriere and Turcotte (1994) developed the model into 3-D fractal cellular-automata models. Their models could produce the GutenbergRichter law and simulated foreshock/aftershock as well. They claimed no systemic precursors observed before great shocks. All of these researches were considered support to Geller's conclusion (Geller et al. 1997) that earthquake cannot be predicted.

However, we must be careful when making such kind of conclusion. Although simulation is an effective way to study complex phenomenon, the premise is that models resemble realistic world. In the sand pile model, the logarithm relationship was simulated, but the sands were put into cells randomly, and it did not resemble the real earthquake preparing process because the tectonic movement had regularity. Global Positioning System (GPS) showed that tectonic movement is uniform in a time scale of decades. What's the case in greater time scale? Hot materials went up from the core mantle boundary (CMB) forming plume named "hot spot" and leaves a chain of volcanoes at moving oceanic plate. The Hawaii hot spot in the Pacific Ocean made the Hawaii Island chain. Based on the distance from Hawaii and the age of volcanic rocks, the moving velocity of the Pacific plate can be estimated in different geological period. It is found that the plate movement is roughly uniform in time scale of tens of millions years. It means that stress evolution within plates, which took tectonic movement as boundary condition, had regularity. Although the plate movement may have small fluctuates randomly, it is by no means completely random. Take shooting as an analogy. If one shoots complete random, then the placement of bullets cannot be predicted. By contrast, if one shoots aiming at a target, then the placement of bullets also affected by some random factors but it will obey a normal distribution instead of a complete randomness.
In the above analogy, a linear system is implicitly supposed. In the real world, a lot of dynamic systems are nonlinear. It means these systems are highly sensitive to initial condition. The phenomenon was observed by Lorenz when he tried to solve the nonlinear equations of atmosphere dynamics. In December 1979, Lorenz said in a lecture in Washington, "the flap of a butterfly's wings in Brazil set off a tornado in Texas", and the phenomenon was called "butterfly effect" (Lorenz 1963). Because results are highly sensitive to the initial state, it is impossible to do long-term prediction for a nonlinear system. Nonlinear system has it's regularity of course. It seems that strange attractors exist in the phase space; the system would evolve to some stable states. Although the stable states could be infinitely many, the distribution of these attractors has its own patterns. Systems like this will evolve to the state called "chaos". Even for nonlinear system, it is still possible to do short-term prediction. It was verified by a familiar fact that weather could be predicted in a time scale of several days. What is the timescale in which earthquake could be predicted? We need to do lots of research to answer this question.

Some scientists suggest that it is necessary to distinguish "forecast" and "prediction", but these two words are synonyms in English, and both are used in other subjects such as weather forecast/prediction. There is no uniform definition to distinguish the two words in earth science (Kerr 1992; Marzocchi and Zechar 2011). Some people suggest that "prediction" refers to one predicts when and where an earthquake would be happen and the magnitude as well, while "forecast" gives the probability of an earthquake would happen in a time-space window. Some of the others suggest that "prediction" refers to precise prediction, while "forecast" refers to imprecise prediction. Some scientists believe that earthquake cannot be predicted but can be forecasted and have been doing research on earthquake forecast (Kagan and Jackson 2000). The 2011 ICEF report tried to define the term of prediction and forecast (Jordan et al. 2011), considering that predictions as deterministic statements, and forecasts as probabilistic statements. However, as early as 1976, the National Research Council, US National Academy of Sciences had pointed out (Allen et al. 1976): in addition to "An earthquake prediction must specify: the expected magnitude range, the geographical area within which it will occur, and the time interval within which it will happen with sufficient precision .... Moreover, scientists should also assign a confidence level to each prediction." We consider that all kinds of prediction should come with probability because few predictions are affirmative. In China, scientists usually predict earthquake without probability because they could not calculate the probability rather than their affirmative. There is no exact statistics of success ratio of different 
kinds (long term, intermediate term and short-imminent term) of earthquake prediction in China (Shi et al. 2001). It means that the probability for each prediction is quite low. It is worth to note that the prediction is meaningful only when the probability is significantly higher than background seismicity. If the accuracy of the "forecast" would be raised, and the time-space window shrank, then how much distinction exists between "forecast" and "prediction"? It is not worthwhile to distinguish the two words "forecast" and "prediction". We should put effort on evaluating the efficacy of earthquake prediction in a scientific way, which is based on large amount of instance of earthquake prediction for any methods (Shi 1992; Shi et al. 2001).

\section{Present situation of earthquake prediction in China}

In the 1960s, people expected precursors of earthquake. They thought earthquake must come follow a precursor

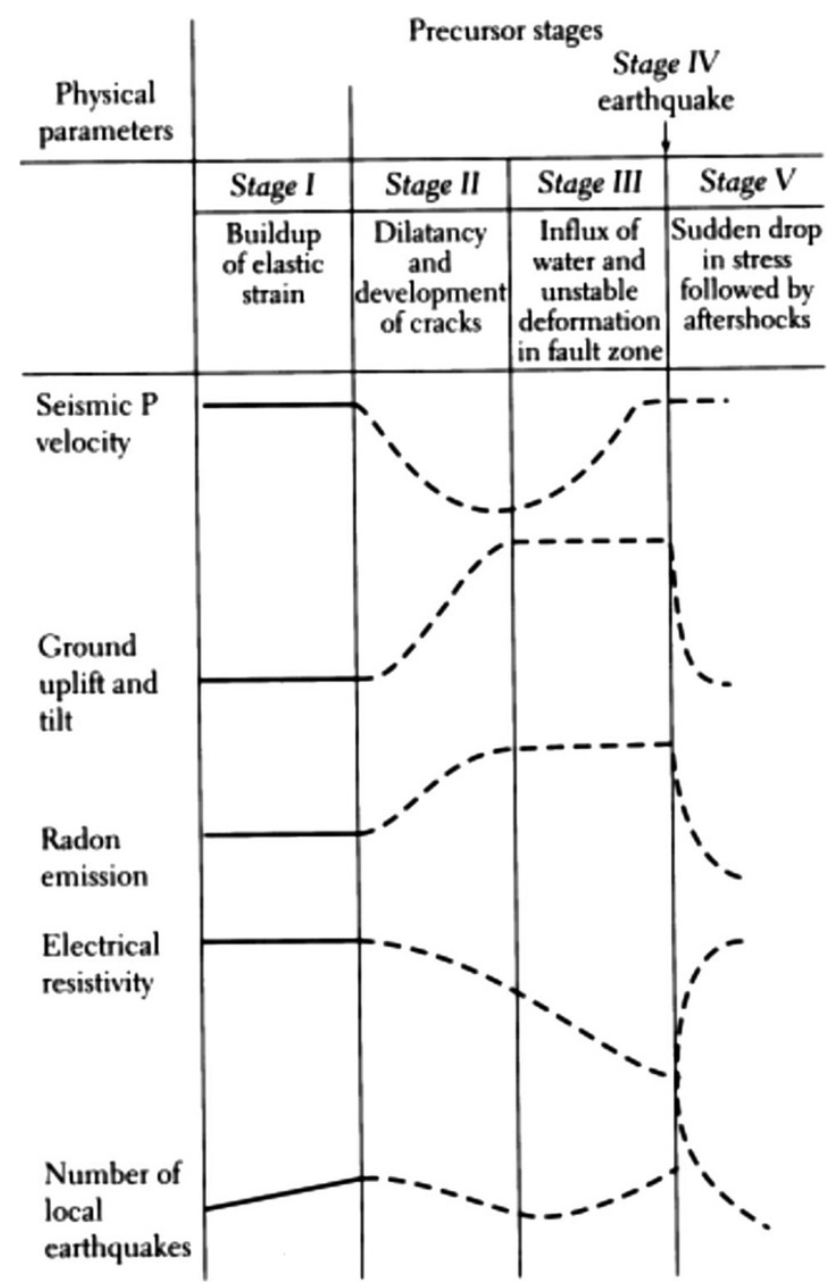

Fig. 2 Supposed earthquake precursors in 1960s-1970s
(Fig. 2). People cannot predict earthquake because lack of stations and techniques to detect precursors, so more than 1,300 seismic stations were planted in China. 1,271 stations were also planted to observe precursors, including 358 to observe strain, 294 to observe electromagnetic field, 619 to observe fluid (Working Group for Re-examination of Wenchuan Earthquake Prediction and CEA 2009). Although we had so many stations, we failed to predict the 2008 Wenchuan $M_{\mathrm{w}} 7.9$ earthquake. It is time to think over whether the number of stations is crucial in earthquake prediction. Chen suggested three difficulties in earthquake prediction: Impenetrability of the Earth, lack of major events and the complexity of seismogenic process (Chen 2008). In practice, it is noticed that some anomalies were not followed by major earthquakes while some great earthquakes did not have detectable precursors before its occurrence.

Maybe we have not found the best precursor? People have been trying hard to find a reliable precursor without failure or false alarm. Chinese scientists tried many revised or newly proposed methods. From time to time, there were researchers declaring that their methods were superior, but none of them was accepted as "panacea". It seems that any single kind of precursor has its limitation. Can we improve our achievement by combining them together? The simplest way is to count the total number of anomalies of all kinds and find the relationship with great earthquakes. Figure 3 shows although this pattern seems to work for several periods but failed also for the 2008 Wenchuan $M_{\mathrm{w}} 7.9$ earthquake.

Some people think that it is easy to do short-term prediction on weather while it is easy to do long-term prediction on earthquake. But when taking a glance of Fig. 4, one can find out that Japanese seismologists have been expecting a great earthquake in the Tokai of Japan. The 2011 Tohoku $M_{\mathrm{w}} 9.0$ earthquake embarrassed them. Japanese released earthquake probability map every year since 1979. The earthquakes which killed more than 10 people are also plotted in Fig. 4. One can figure out most of them occurred in the areas assigned with low probability. The situation forces us to find new perspectives on earthquake prediction.

Earthquake prediction can be classified by time scale into long term, middle term and short term. Compared with weather forecast, it can also be classified by methods into 3 kinds: empirical prediction, statistical prediction, and numerical prediction. Both empirical and statistical predictions are based on precursors, although people try to understand the physical meanings behind the phenomena. Numerical prediction is, however, based on physical laws. In China, earthquake prediction is still in the stage of empirical and statistical prediction.

Methods and applications of earthquake prediction in China are reviewed by (Mei et al. 1993; Zhang et al. 2001). In summary, mid-term and long-term prediction rely on 


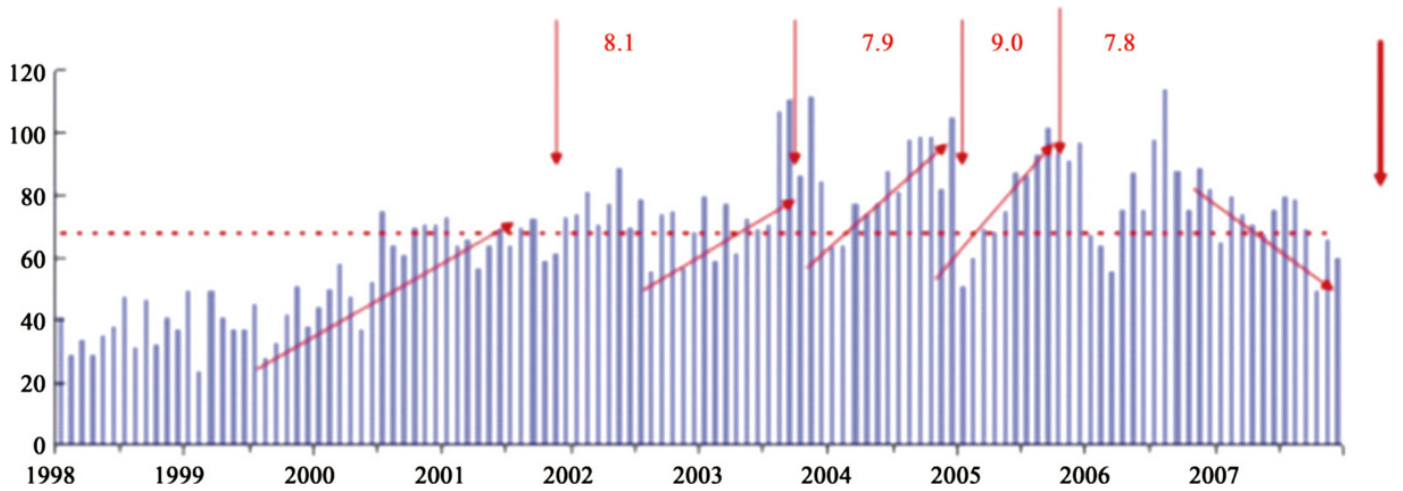

Fig. 3 This chart shows number of seismic anomalies against time in China between 1998 and 2008. Before 2006, it seems that major earthquakes take place when the number of seismic anomalies increase, but the Wenchuan $M_{\mathrm{w}} 7.9$ earthquake breaks the pattern

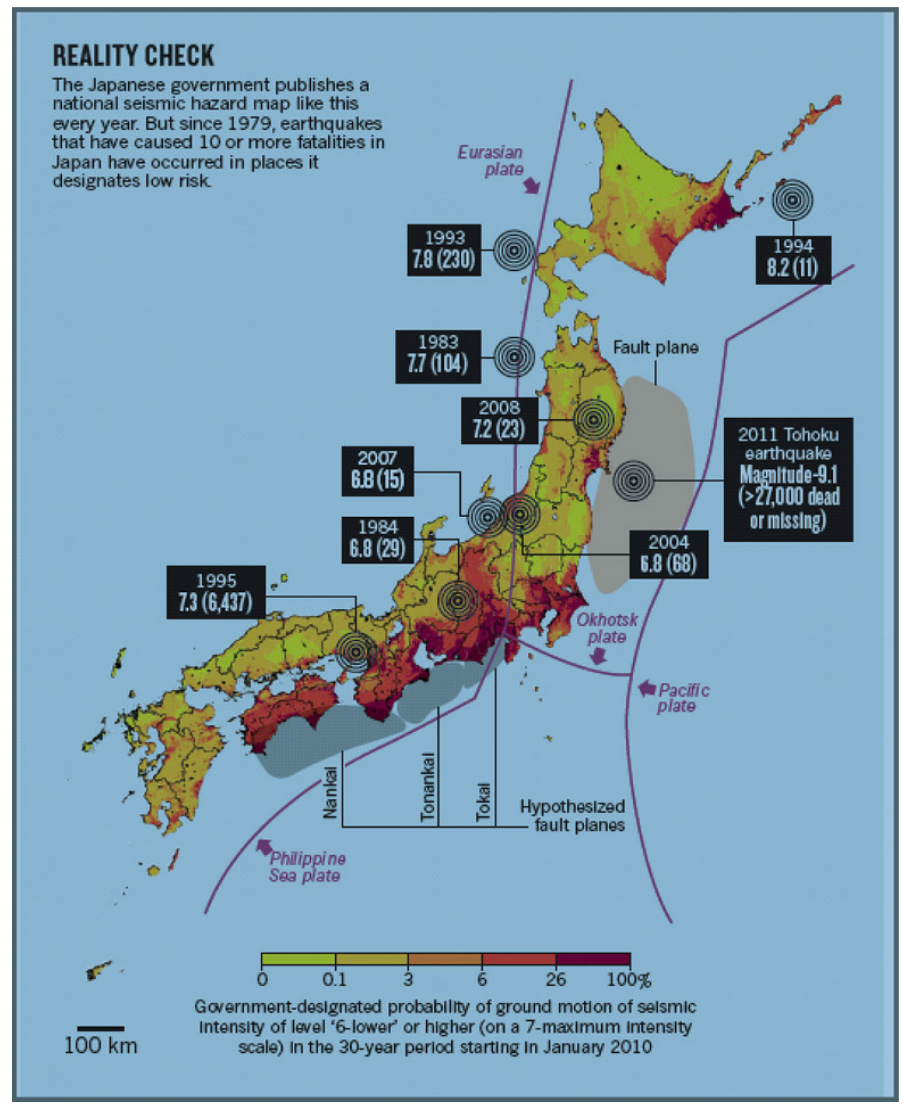

Fig. 4 Government-designated probability of ground motion of seismic intensity of level '6-lower' or higher (on a 7-maximum intensity scale) in the 30-year period starting in January 2010. The Japanese government publishes a national seismic hazard map like this every year. But since 1979, earthquakes that have caused 10 or more fatalities in Japan have occurred in places it designates low risk (Geller 2011)

seismicity, seismogeology, and space geodesy, while shortterm prediction pay additional attention to precursors of crustal deformation, electromagnetic field, underground water, etc. Newly proposed methods such as satellite thermal infrared and infrasound were also used for shortterm prediction. Chinese scientists expect to "diagnose" earthquakes by precursor directly, while scientists in western countries try to understand the basic physics before using any precursor in practice. Different types of models were developed to explain precursors. One example is dilation-diffusion model developed by American scientists (Press 1975). In this model, strain energy is accumulated in rocks at the beginning. In areas where deformations are large enough, many micro-cracks are generated, then dilation becomes the leading factor and precursors appear. At this stage, precursors reflect changes of physical property of rocks due to micro-cracks. Cracks minify the ratio of velocity between $\mathrm{P}$-wave and $\mathrm{S}$-wave. The humidity 

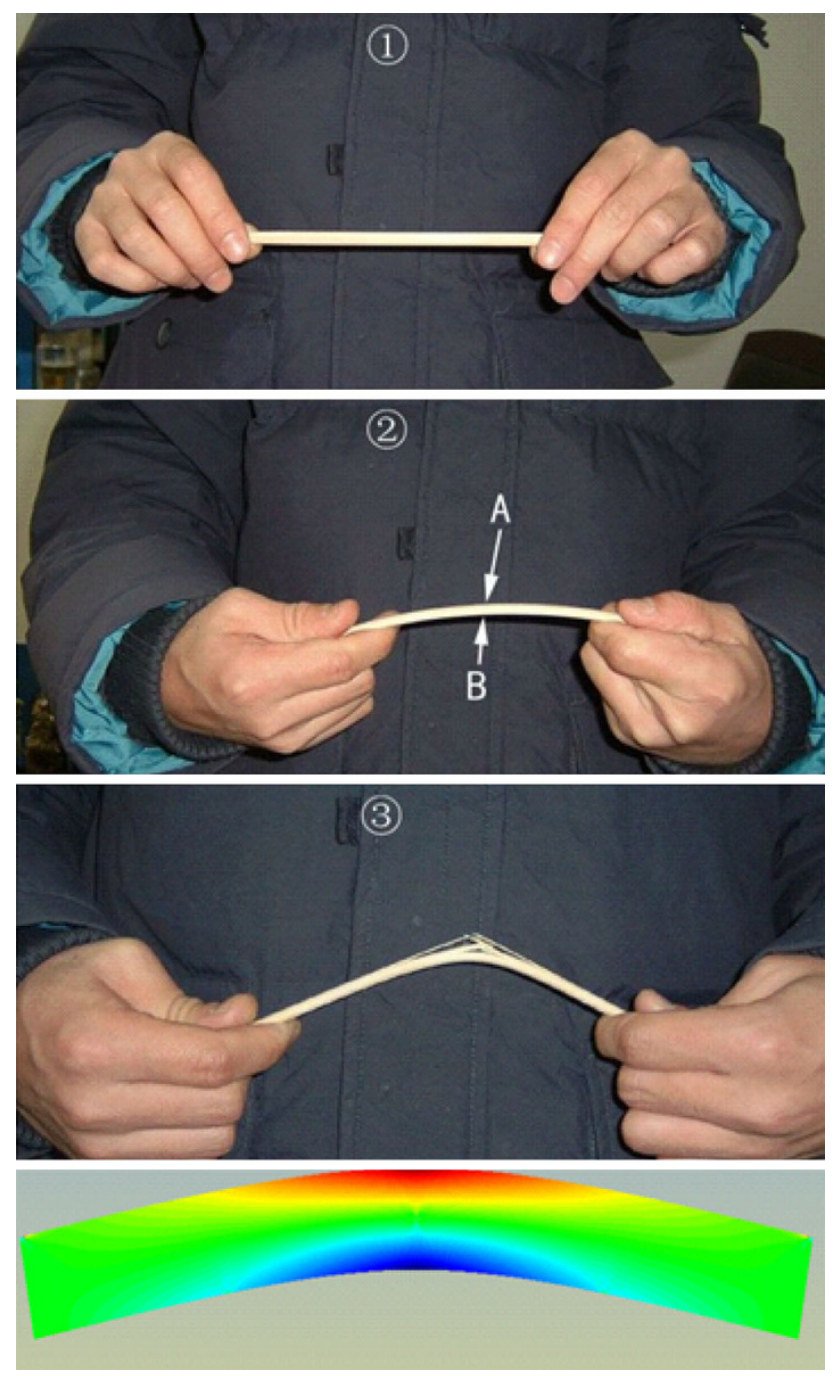

Fig. 5 Mimic the failure process of an elastic plate by chopsticks. The figure at the bottom shows positions of maximum stress (red color) and minimum stress (blue color)

content of rocks affects electric resistance. Increasing micro-cracks may cause the underground water unsaturated and downgrade the pore water pressure. As a result, seismicity decreases. After the dilation stage, water diffuses into the dilation area and makes the pore water pressure goes up. As a result, the seismic wave velocity and seismicity increase. The main shock follows this stage and rocks go back to the initial stage. But in practice, precursors do not always appear before main shock.

Statistics are used broadly in earthquake prediction not only for looking for simple relation between earthquakes and precursors, but also for revealing physical mechanics. Russian scientist Keilis-Borok, etc., developed a series of algorithms (Keilis-Borok 2002) to predict earthquakes based on earthquake catalogs. Vere-Jones, etc., in New Zealand developed stress release model and ETAS model to characterize the series of main shock and after shock
(Vere-Jones 1995). These methods are also adopted in Chinese research. Weather forecast is done frequently, and the experience is accumulated day by day. By contrast, great earthquakes are really rare, so it is very difficult to find statistical law from the small sample. It is a big obstacle for empirical earthquake prediction.

It is very difficult to predict earthquakes. When we deal with complex problems, it is a good idea to study a simpler case at first. While bending a chopstick (Fig. 5), we know that it would break somewhere near the middle point of the upper surface. The reason is when bending the chopstick, the largest tensile stress would appear at the middle point of the upper surface, and the largest compression stress would appear at the middle point of the lower surface. For generic materials, compression strength is larger than tensile strength. As a result, if we know the strength of the chopstick and the loading rate, we can predict when and where the break would occur.

This simple case reveals that strength of the material and loading stress are critical factors for break. As the stress accumulates, additional phenomenon would appear. Microcracks would be developed, precursors of electromagnetic property or pore fluid would appear, etc. We should notice the derived precursors, but more attention should be put on loading stress which is one of the critical quantities. If we could compute the stress distribution under specific loadings, it is possible to foresee the risk of major break.

Chinese scientists thought back to the failure of prediction for the 2008 Wenchuan $M_{\mathrm{w}} 7.9$ earthquake. They proposed to do more research on the physical fundamentals of earthquake prediction and change from empirical prediction to physical prediction. But what is physical prediction? How to achieve physical prediction? We need to discuss it and make clear understanding of it.

\section{Numerical prediction based on physical principles}

Numerical weather forecast is done by solving equations of fluid mechanics and thermal dynamics under specific initial conditions and boundary conditions. It is based on physical principles and takes advantage of high speed computers. The initial and boundary conditions are obtained from observations. The idea was formed in 1920s but not implanted until 1950s when high speed computers were used. Weather forecast provided a good model for earthquake prediction to follow.

Similar ideas can be applied for prediction of earthquakes, i.e., numerical earthquake prediction. It is not enough to understand the physical process qualitatively. The only way to accomplish physical prediction is to solve it numerically. If we know the structure and material property in the Earth, and we could construct equations 


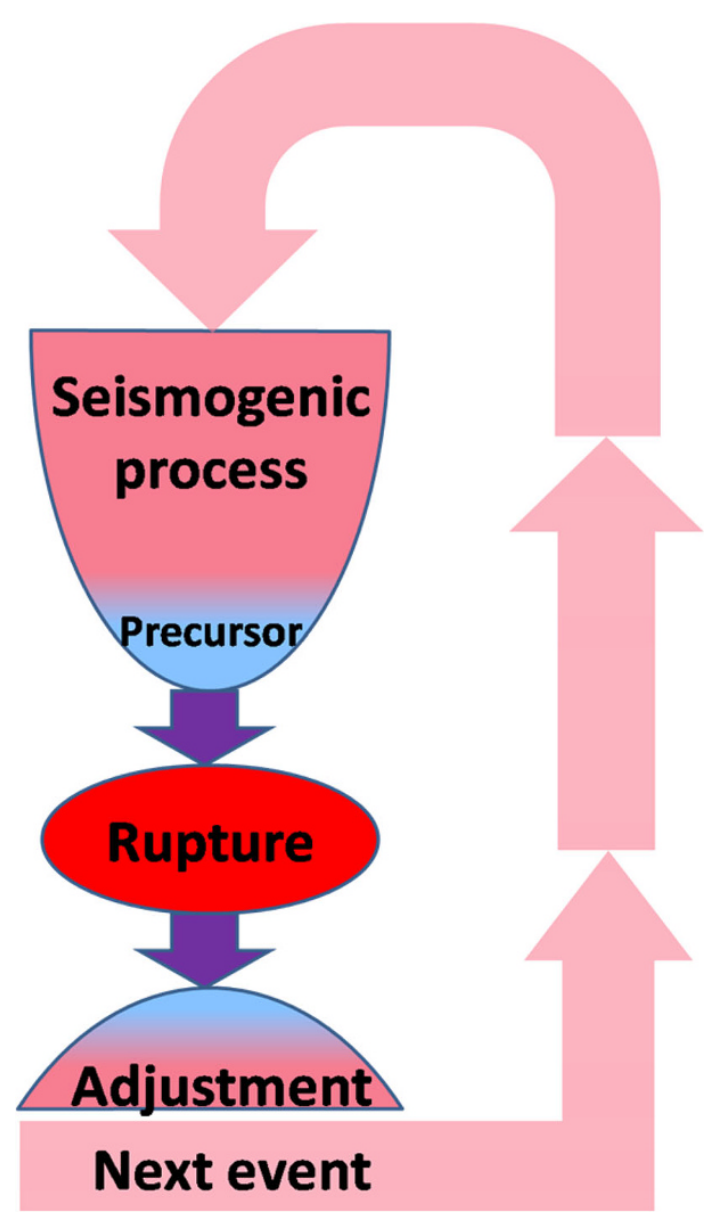

Fig. 6 Major stages in an earthquake cycle

based on continuum mechanics of viscoelastoplastic body, thermal dynamics, failure criteria of rock mass, and constitutive relations of faults. Furthermore, if we could obtain initial and boundary conditions, such as directly from GPS observations, stress measurements, and indirectly from geological surveys and historical and instrumental seismic observations, then we could solve the equations, find out regions of highest strain energy accumulation rates and regions most close to failure occurrence, therefore, to be able to predict the most probable location and magnitude of an earthquake. We also could predict when the earthquake would happen if we know the loading rate and the failure strength. Uncertainties in the model and in boundary and initial conditions may lead to different scenarios of evolution computed; probability of occurrence of different scenarios may be derived from error distributions of each model parameters. Numerical earthquake prediction can thus forecast several forthcoming scenarios and their occurrence probability based on computation of the stress evolution and elastic energy accumulation.

Clearly, there are five important factors for numerical prediction: (1) understand the physical process and construct equations based on physical principles, (2) ability to numerically solve these equations, (3) knowledge of structures and material properties in the Earth, (4) boundary conditions and their variation with time, (5) initial conditions. What is the situation of these factors now?

Figure 6 illustrates main processes of an earthquake, they are earthquake preparation, occurrence and development of faults, adjustment after the earthquake, and preparation for a new earthquake. The preparation is a long process, usually take decades to thousands of years. When an earthquake is going to happen, the rocks would deform nonlinearly and precursors could appear. By contrast, it is a really fast from small cracks to a big earthquake. It only needs some $10-100 \mathrm{~s}$. But so-called slow earthquake or silent earthquake were discovered recently (Zhang et al. 2005). The failure process of these types of earthquake is slow and only seismic waves of long wavelength were emitted or no seismic wave emitted. In the process of adjustment after the earthquake, surrounding mediums continue to deform and stress could vary notably in months or years.

What about the failure process? Continuum mechanics (elastic, viscous, viscoelastic, plastic) is used in scientific and engineered problems with success. We know less about the crack process, and this is why we could not catch precursors. But we do know some failure criteria of rocks, and the constitutive relation during the faulting process. Therefore it is possible to explore some preliminary numerical simulations.

The ability of solving equations was developed rapidly in recent years. In China, more and more high-speed computers were used in many institutions. Algorithms and softwares were also developed both in China and abroad. One way to solve partial differential equations is breaking the continuous medium into discrete elements. In the past, we can only deal with tens of thousands elements and get a solution with low accuracy. Now we can deal with millions of elements and have the ability to simulate geodynamic process with viscoelastic medium, poroelastic medium.

The knowledge of media property in the Earth was increasing. We know them mainly from seismology and experiments of rocks. In recent 5 years, the Chinese government supported the SinoProbe project, 6,160-km deep reflection profiles have been accomplished, which exceed 50 years' work (about 5,000 km) before SinoProbe project. We accumulated more and more data about structure of the Earth and property of rocks. Now we can construct a rough model of the Earth.

Then let us explore the boundary conditions. Boundary conditions could be very complex, and it is meaningful to talk about two basic types: stress boundary conditions and displacement boundary conditions. Stress varies with depth in a complex manner. Rocks in the upper crust behave as brittle 
material and can resist large stresses. In depth, under high temperature and confining pressure, rocks may be ductile and resistance to stresses may be lower. The strength of crust varies with depth. Some places may vary from brittle to ductile then back to brittle or less ductile. Due to the complexity of earth structure, it is hard to give stress boundary condition varying with depth. The deepest drilling is only with a depth of $12 \mathrm{~km}$ located at Kola Peninsula in Russia. The second deepest drilling is in Germany with a depth of $9 \mathrm{~km}$ and can measure terrestrial stress above $7 \mathrm{~km}$. We know little about terrestrial stresses in depth. Although we can study it with seismology, it is hard to determine the magnitude. We know less about how stresses vary with time. In summary, it is very difficult to determine stress boundary conditions.

Space geodesy (GPS for example) provides velocity data of tectonic movement nowadays. Geologists state that the velocity may be constant in geological time (tens of millions years). Take Hawaiian island chain as an example. The hot spot left a trace on the Pacific plate as the plate moving. There is a linear relation between the ages of volcanoes and the distance from the volcanoes to Hawaii. Research of the relationship showed that the moving direction of the Pacific plate changed at 70 million years ago but the speed kept constant. The velocity is kept constant in time scale of decades according to GPS data. The relative velocity between the India plate and the Tibet plateau almost keeps constant although it increased a little after the 2004 Sumatra $M_{\mathrm{w}} 9.2$ earthquake for 1 year. Oceanic plates are rigid; as a result, the velocity at depth is the same as the ground velocity. Continental plates could be ductile, but we also can use ground velocity as velocity at depth with care in preliminary simulations.

In summary, we need and could start study earthquake preparing process, although it is difficult to determine boundary conditions.

Our knowledge about initial state of terrestrial stress tensor is even poorer. We have little data of 3-D terrestrial stresses and have limited ability to measure it today. But we can give some preliminary boundary conditions and have done considerable progress on the other three factors. The situation is that we cannot predict earthquakes now but can do some research on theories and methods of numerical earthquake prediction. In next section, we will introduce some work about earthquake preparing, and effects caused by an earthquake. We can get new insights by doing numerical simulation based on physical principles.

\section{Researches on earthquake preparing, earthquake and adjustment after an earthquake}

Take the 2008 Wenchuan $M_{\mathrm{w}} 7.9$ earthquake as an example to study earthquake preparing. The popular story is: India plate subducts into the Eurasian plate which make the Tibetan plateau uplift quickly. Mass of the Tibetan plateau flows to the east and squeezes the Longmenshan fault zone. This process is obstructed by Sichuan basin and creating stress there for a long time. At last, the strain energy was released at Beichuan-Yingxiu as the earthquake. This story is not wrong, but too brief to give the details. There are many questions about the preparing process not answered. Why was the earthquake located under Longmenshan? Why was the earthquake happened at a depth of no more than $20 \mathrm{~km}$ ? Why was the fault thrust at southwest part but dextral strike-slip at northeast part? To answer these questions quantitatively, we need do numerical simulations.

We constructed a 3-D geological model of this area. Seismology revealed structure of this area at depth (Figs. 7, 8; Wei et al. 2010). Researches in laboratories and in the field give us knowledge about lithology and elasticity of rocks. We can also estimate temperature at depth according to terrestrial heat flow density and velocity of seismic waves (related to temperature). Then we got viscosity by combining temperature and laboratory results (Shi and Cao 2008). Under high temperature and high pressure, rocks are no more elastic but viscoelastic. They behave as solid in short-time scale but as fluid in long-time scale (like ice could flow in long-time scale but looks like solid). If we measure post-earthquake deformations, then we could match the field data with laboratory result to determine viscosities.

Figure 9 illustrates a 3-D viscoelastic finite element model of western Sichuan. The Young's modulus increases with depth. Viscosities vary in a more complex way: The upper crust has high viscosity while lower crust has low viscosity. Mantle rocks beneath Moho have higher viscosity than the lower crust, and decrease with depth due to temperature going up. In the transversal section, the properties of rocks are quite different between plateau and basin. Rocks under the plateau have the lowest viscosity in the model. We start from a zero stress initial state to observe how stresses are accumulated. Boundary conditions are set by interpolating GPS data. Furthermore, we assume that the lower surface can freely move horizontally but cannot move vertically.

We are used to regard rocks as ideal elastic material at normal temperature and pressure. The result of ideal elastic model (Fig. 10) shows that locations of the highest normal stresses and dextral shear stresses on the fault do not match epicenter distributions in Fig. 9. It means that the ideal elastic model cannot explain how the 2008 Wenchuan $M_{\mathrm{w}} 7.9$ earthquake is prepared.

Since rocks are ductile at high temperature and pressure, we give the result of the viscoelastic model. Boundary conditions and initial conditions are described above. When given constant velocities on the boundaries, the 

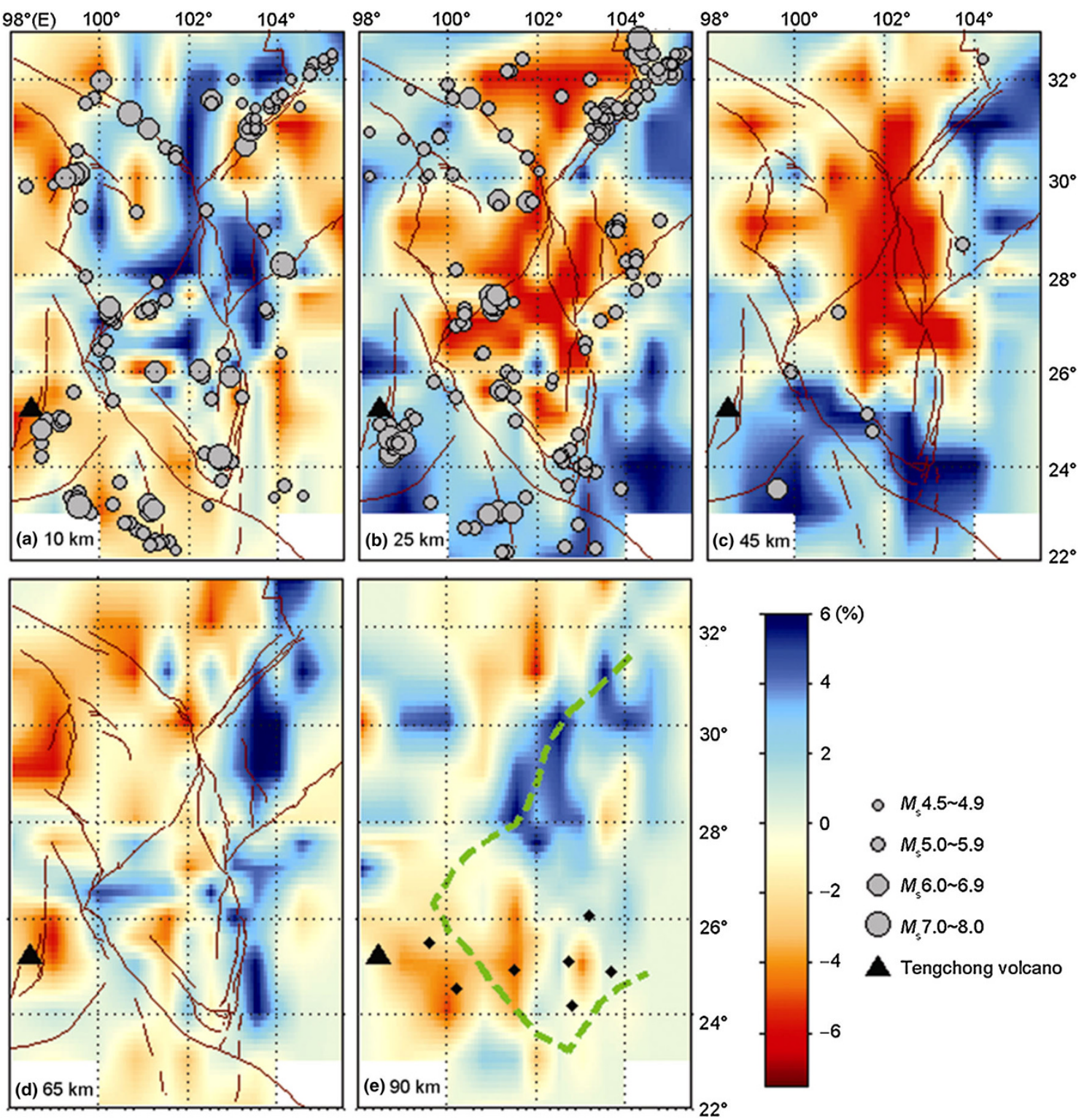

Fig. 7 Map view of P-wave tomography at various depths. Red and blue colors represent slow and fast velocity perturbations in percentage, respectively. Gray dots show the epicenter of the earthquakes $(M>4.5)$. Earthquakes with a focal depth less than $20 \mathrm{~km}$, between 20 and $33 \mathrm{~km}$ and greater than $33 \mathrm{~km}$ are projected onto the image of 10,25, and $45 \mathrm{~km}$, respectively. It shows that the lower crust and upper mantle beneath Sichuan Basin possess high seismic velocity while the lower crust beneath the Tibet possess low seismic velocity (Wei et al. 2010)

viscoelastic model deforms with time. For regions with low viscosity lower crust, the stress accumulation gets into quasi-steady state after hundreds years of transient state. Figure 11 is a map of the rate of stress accumulation. The area in red color (highest stress accumulation rate) covers the bottom of upper crust (10-20 km) in the Longmenshan fault zone where the 2008 Wenchuan $M_{\mathrm{w}} 7.9$ earthquake took place. The area in orange color (high stress accumulation rate) is located on the plateau side where many earthquakes occurred including the 1976 Songpan $M_{\mathrm{s}} 7.2$ earthquake. Few earthquakes occurred in the area in light blue (low stress accumulation rate). Almost no earthquake occurred in the dark blue layers where rocks are ductile. The left part of Fig. 11 shows horizontal stress rate normal to the strike of the Longmenshan fault, highest stress rate concentrates at the south west part of the Longmenshan fault, in agreement with the observed thrust focal mechanism; while the right part shows shear stress rate concentration, maximum occurs at the north east part of the Longmenshan fault which is also in agreement with observed strike-slip focal mechanism there.

From the viscoelastic simulation, we can explain many characteristics of the 2008 Wenchuan $M_{\mathrm{w}} 7.9$ earthquake including location of epicenter, depth, and focal 

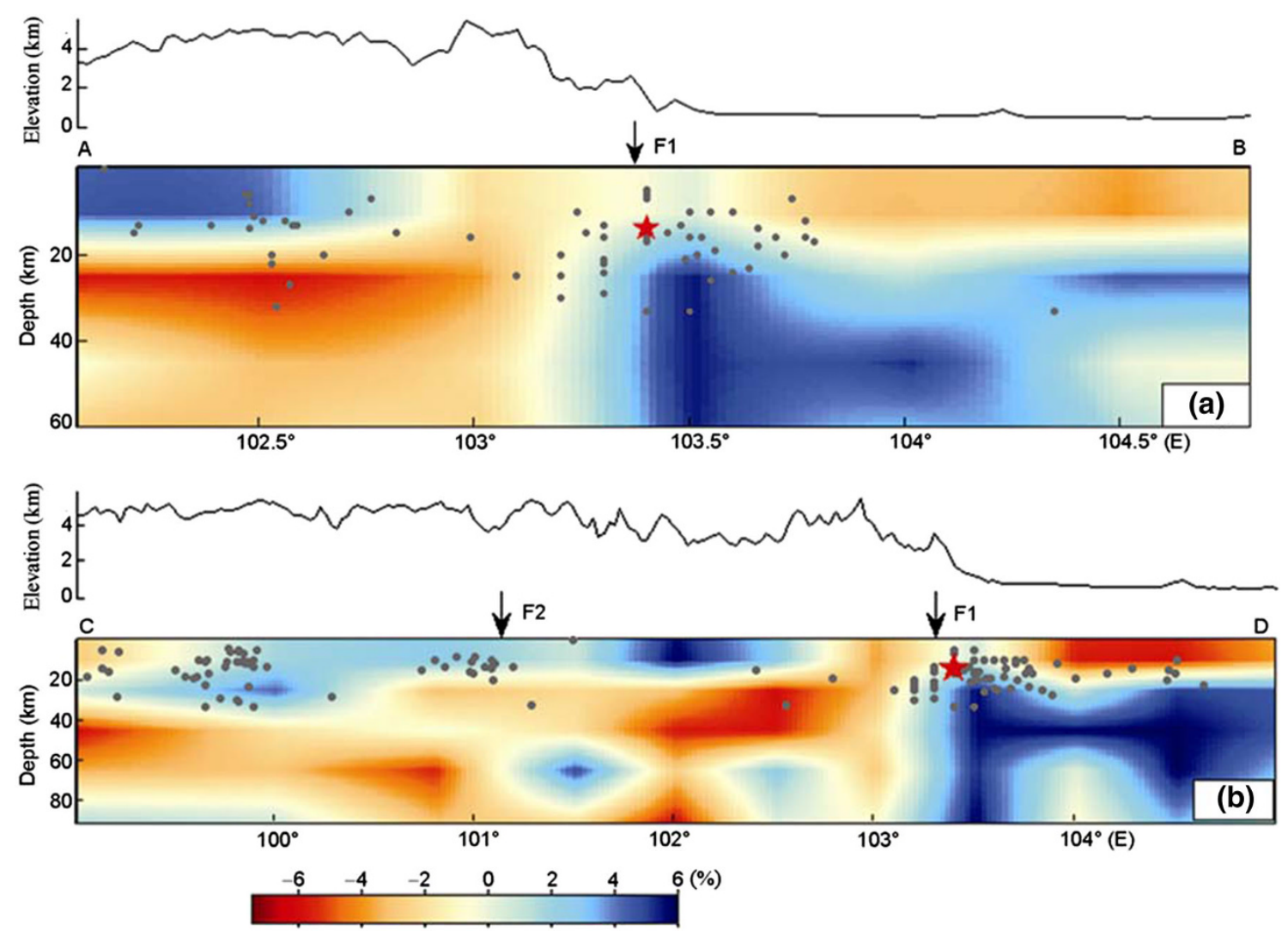

Fig. 8 Vertical cross sections of P-wave tomography in Sichuan-Yunnan region. The red star denotes the Wenchuan main shock. The upper section is passing the epicenter and perpendicular to the Longmenshan. The lower one is an east-west section also passing the epicenter. The surface topography is plotted above each profile. Red and blue colors represent slow and fast velocity perturbations, respectively. The velocity perturbation scale in percentage is shown at the bottom. Gray dots indicate the background earthquakes with magnitude 4.0 that occurred within a $15-\mathrm{km}$ width along each of the profiles. The tomography shows that the lower crust and upper mantle beneath Sichuan Basin possess high seismic velocity while the lower crust beneath the Tibet possess low seismic velocity (Wei et al. 2010)

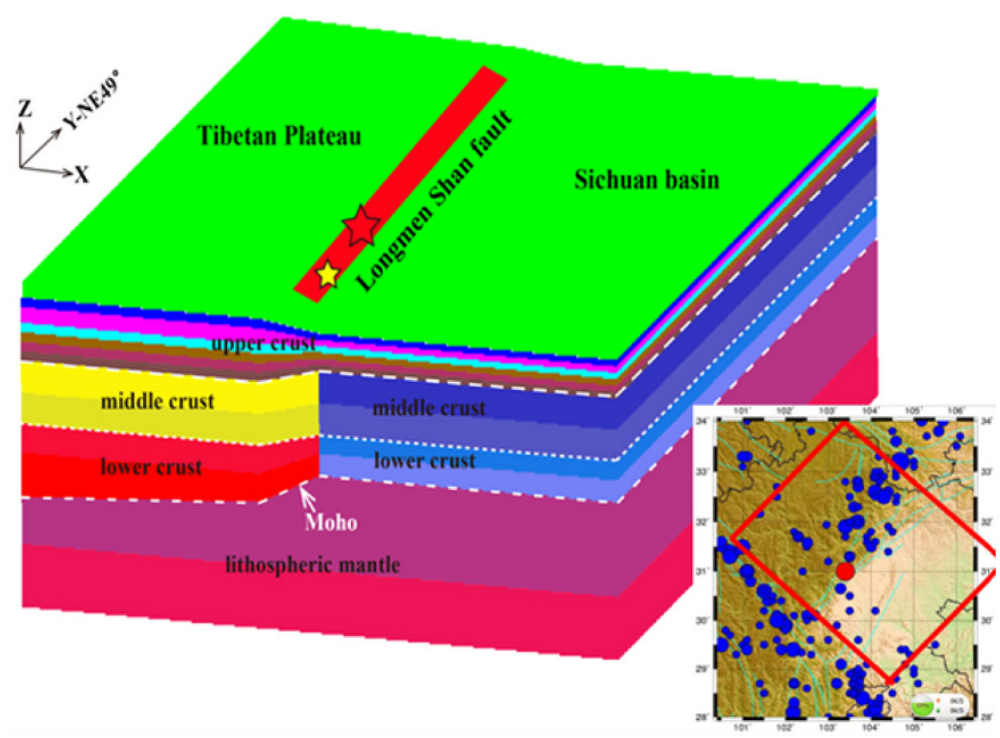

Fig. 9 A layered model of computational domain. The figure at the bottom right corner illustrates the computational domain and distribution of major earthquakes in the vicinities. Notice the absence of major earthquakes in Sichuan Basin and the attendance in Tibet, but the biggest earthquake is beneath the Longmenshan fault zone where is the junction of Sichuan Basin and Tibet (Liu et al. 2012) 


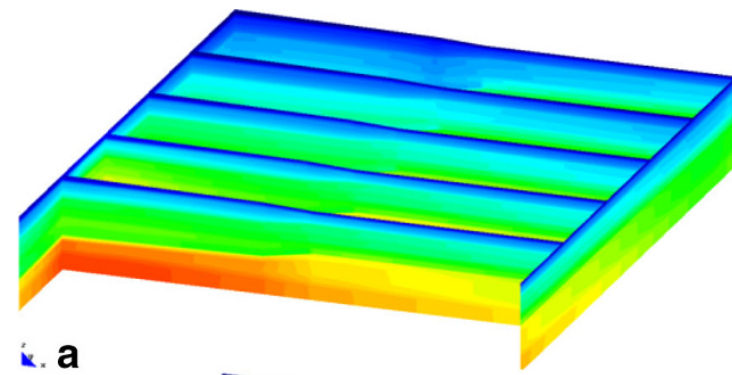

k. $\mathbf{a}$

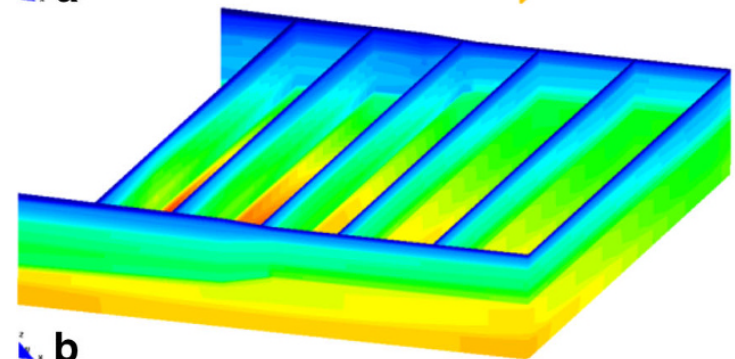

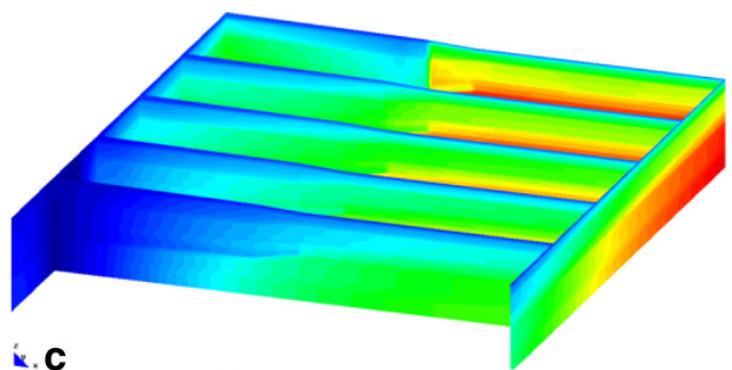

k. C

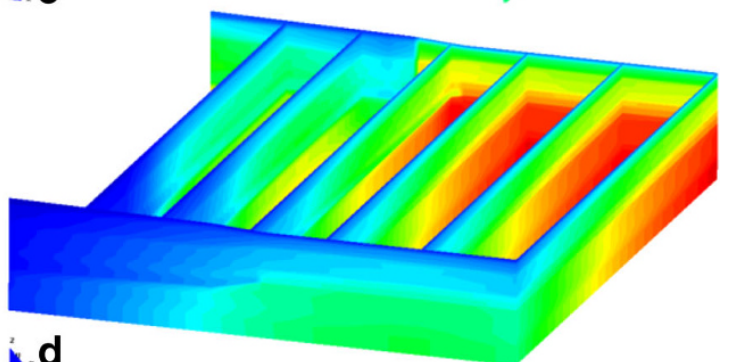

Fig. 10 Stress distribution calculated with elastic model. Stresses normal to the fault are shown in $\mathbf{a}$ and $\mathbf{b}$ on the left column and shear stressed (c) and (d) on the fault are right column. Red color indicates high stress and blue color indicates low stress. There is no clear relationship between the stress distribution and seismicity from this result (Shi 2012)
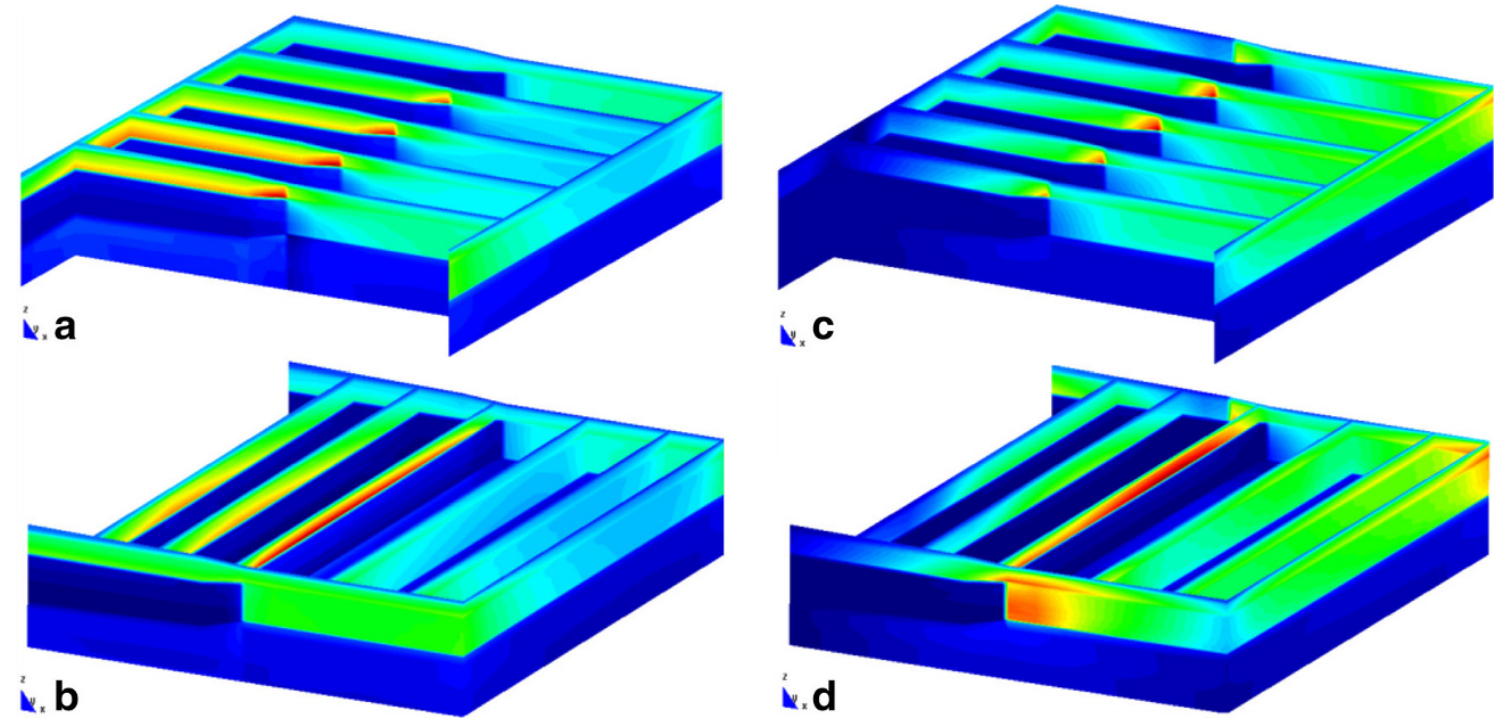

Fig. 11 Stress accumulation rate in quasi-static state calculated with a viscoelastic model. The accumulation rate of stresses normal to the fault is shown on the left column (a) and (b), and rate of shear stresses on the fault (c) and (d) is on the right column (Shi 2012)

mechanism. All of this knowledge cannot be got from qualitative discussion. In the simulation, we do not know the initial stress state and assume it be zero. What we get from the simulation is stress rate but not the absolute stress value, so we cannot predict where is the most dangerous place. If we have enough stress data in the area, it is possible to estimate seismic risk.

Faulting process is also studied by many scientists. One example is the research in Parkfield. Barbot et al. studied earthquake recurrence period in this area based on constitution relation depending on velocity and state (Barbot et al. 2012). We know that static friction is different from dynamic friction. Experiment on the friction of rocks shows that friction in the faulting process is related to velocity and states when velocity changes. They constructed a fault model in Parkfield by reversion based on GPS data and synthetic aperture radar (SAR) data. Their purpose is to simulate the process of earthquake preparing and faulting and to construct a model to predict earthquake recurrence. A typical result of them is showed in Figs. 12 and 13. 

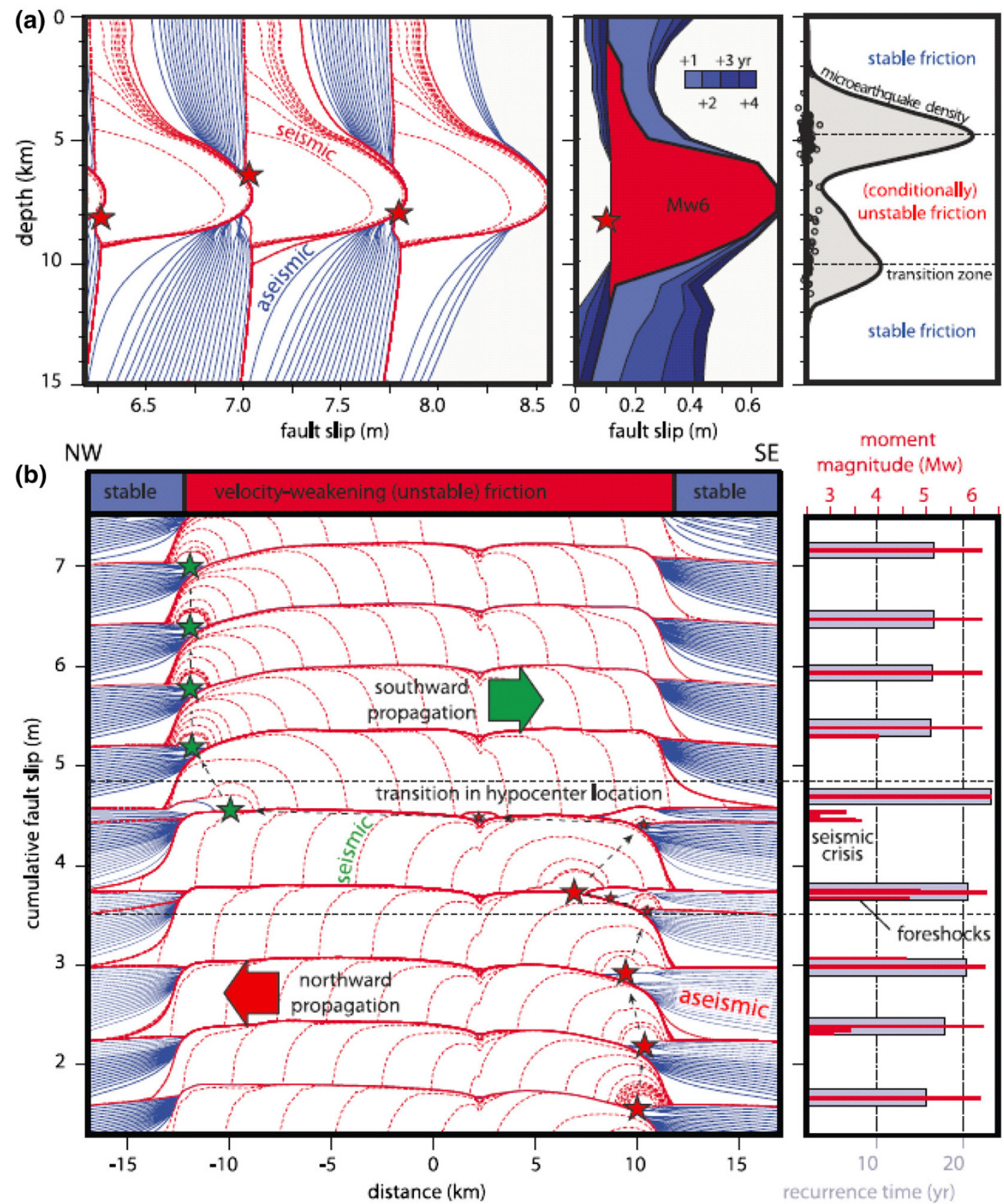

magnitude (Mw)

(b)

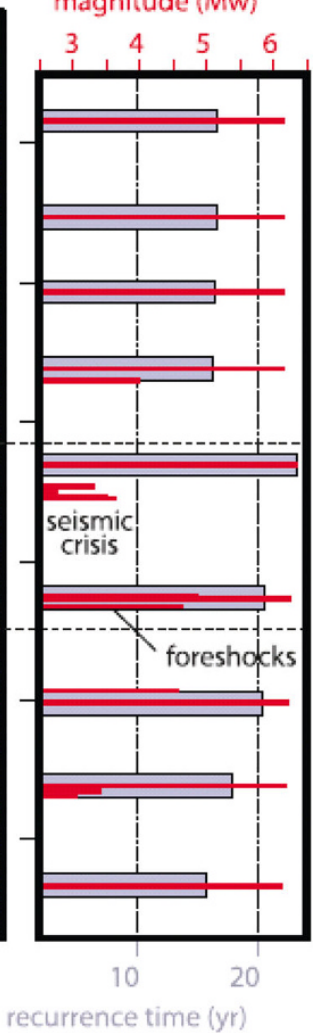

Fig. 12 A simulation of earthquake preparation, earthquake events, and propagation with the purpose of constructing a predictable model of seismic cycles. a Depth profiles in the middle of the seismogenic zone (SZ) comparing the modeled history of fault slip for three events to the one inferred from our inversion of InSAR and GPS data in the period 1999-2010. The red stars indicate the location of hypocenters. The seismicity concentrates around the area of maximum coseismic slip. b Horizontal profiles in the middle of SZ, at 7.5-km depth, showing a series of 11 simulated ruptures. The series captures a complex transition of hypocenter location from one side of the SZ to another, punctuated by foreshocks and a seismic crisis consisting of $M_{\mathrm{w}} 2.0-4.0$ earthquakes and giving rise to the longest recurrence time of an $M_{\mathrm{w}} 6.0$ quake. The red-dashed profiles represent cumulative coseismic slip at 1-s intervals; the blue solid profiles are cumulative aseismic slip at 1-year intervals taking place during the post and interseismic periods. Some of the events have foreshocks. The cracks may develop form north to south or from south to north. The period of seismic cycle of magnitude of 6 is about 20 years which is corresponding to observations (Barbot et al. 2012)

Adjustment of stress after earthquakes is also very important because the amount of stress change could be as large as stress accumulation over years. We calculated the displacement and stress change in North China caused by the
Tohoku $M_{\mathrm{w}} 9.0$ earthquake in 2011. We applied unstructured mesh to the Earth and self adaptation technique. Displacement gradients are quite high near the fault surface of slip; therefore, very dense element grids must be used to 


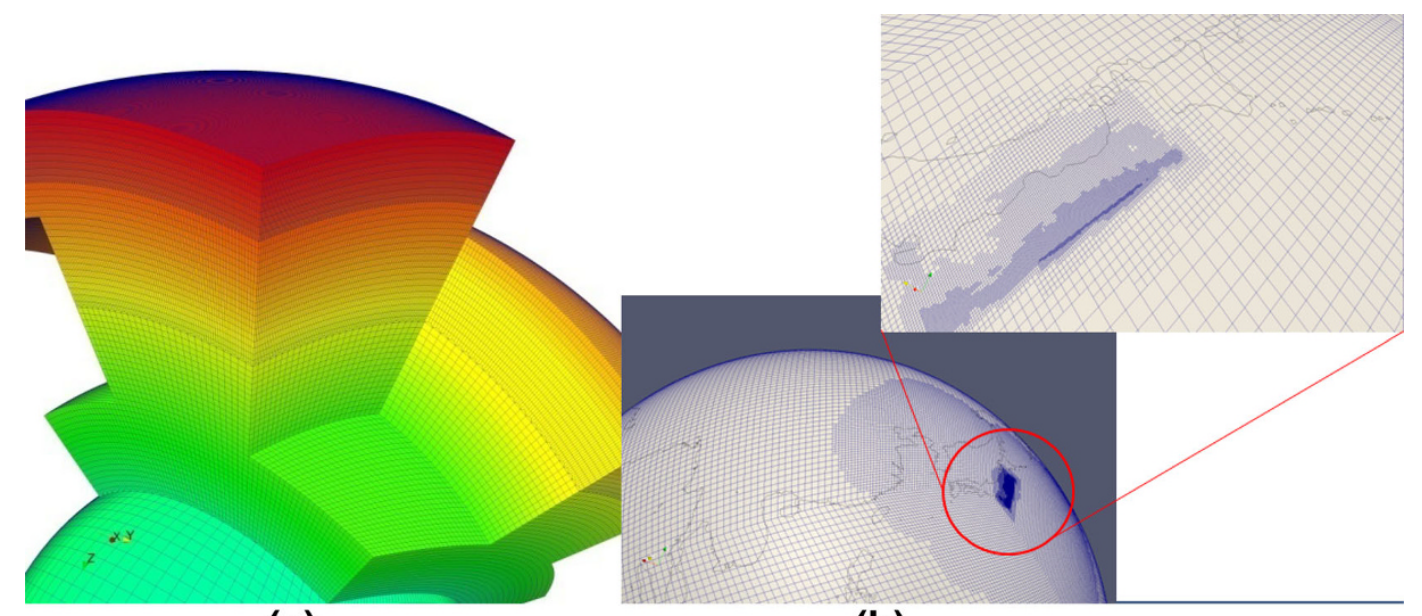

(a)

(b)

Fig. 13 3-d FEM mesh of the Earth. a Structural mesh b adaptive refinement in the vicinity of the epicenter of the $2011 M_{\mathrm{W}} 9.0$ Tohoku earthquake

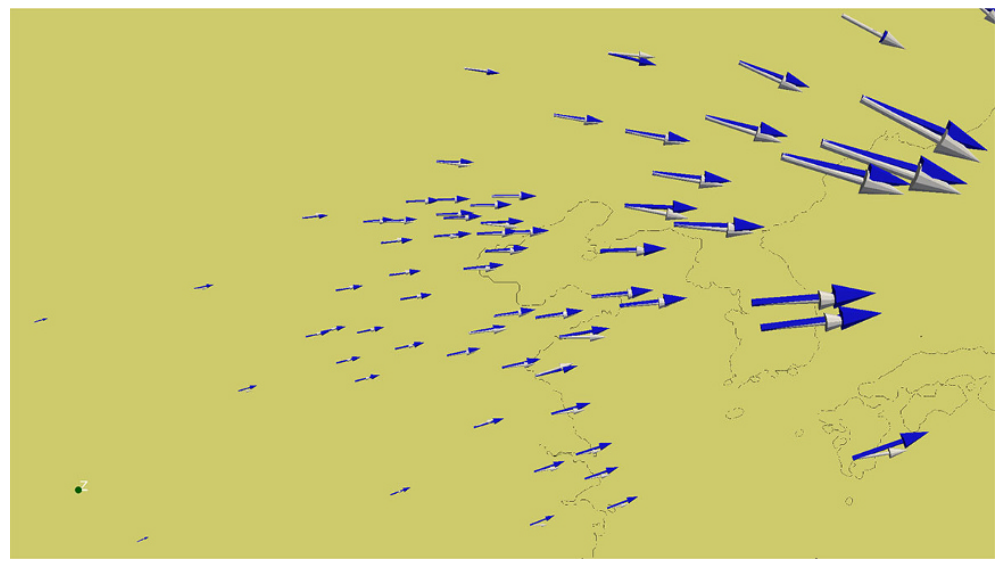

Fig. 14 Coseismic displacement in East Asia caused by the $2011 M_{\mathrm{W}} 9.0$ Tohoku earthquake. White vectors indicate observations by GPS. Blue vectors are results of our simulation

guarantee adequate accuracy of the calculated nodal displacements. The amount of total element is over 4 million. Elements across the fault have size of $0.2 \mathrm{~km}$ to allow the simulation of fault slip. In North China, the element size is $20-40 \mathrm{~km}$. This density of grids is necessary for FEM computation, and it has no direct relation with seismic resolution of crustal structures. Figure 14 shows co-seismic displacement calculated in our simulation. Figure 15 shows co-seismic stress change in North China.

The tectonic stress is supposed to be NNE-WSW compression generally despite some exceptions. Focal mechanism of earthquakes in this area is according with this assumption, such as the 1966 Xingtai $M_{\mathrm{s}} 6.8$ and $M_{\mathrm{s}} 7.2$ earthquakes, the 1967 Hejian $M_{\mathrm{s}} 6.3$ earthquake, the 1969 Bohai $M_{\mathrm{s}} 7.4$ earthquake, the 1975 Haicheng $M_{\mathrm{s}} 7.3$ earthquake, and the 1976 Tangshan $M_{\mathrm{s}} 8.0$ earthquake. The 2011 Tohoku $M_{\mathrm{w}} 9.0$ earthquake reduced compression stress in North China in magnitude of $1-5 \mathrm{kPa}$. The annual strain rate in this area is at magnitude of $10^{-9}$, the compression stress increases $0.25 \mathrm{kPa}$ per year. This implies the compression stress reduction in North China that is equal to the amount of tectonic stress accumulation for 4-20 years. It contributes to put off earthquakes with focal mechanisms like the $1976 M_{\mathrm{s}} 8.0$ Tangshan earthquake by 4-20 years. In the past, we tried to find statistical relationship between an earthquake and seismicity, but now we can discuss the physics from numerical simulation.

It is worth to point out that we did not assert the reduction of compression stress prevent great earthquakes completely. It depends on stress field as well as fault strike, dip, and potential slip direction. The friction on a fault is given as: $\tau=\mu \sigma_{n}$. Increasing $\tau$ or decreasing $\sigma_{n}$ both promote an earthquake. Coulomb stress variation ( $\left.\Delta \mathrm{CFS}=\Delta \tau+\mu \Delta \sigma_{n}\right)$ is introduced here to count the attribution to an earthquake. A positive $\triangle \mathrm{CFS}$ means the 


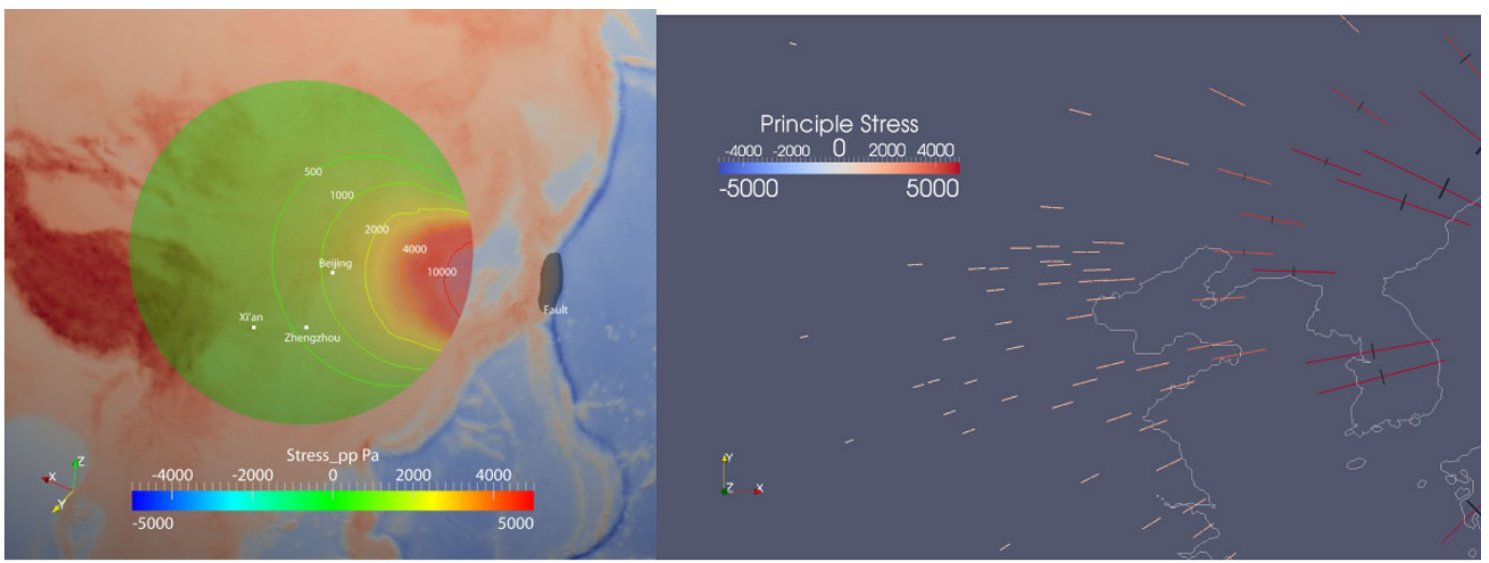

(a)

(b)

Fig. 15 Calculation of farfield must take account of the geometry and layered structure of the Earth as well as lateral heterogeneity. a Normal stress changes along the $\mathrm{E}-\mathrm{W}$ direction. b Maximum and minimum horizontal principal stress changes

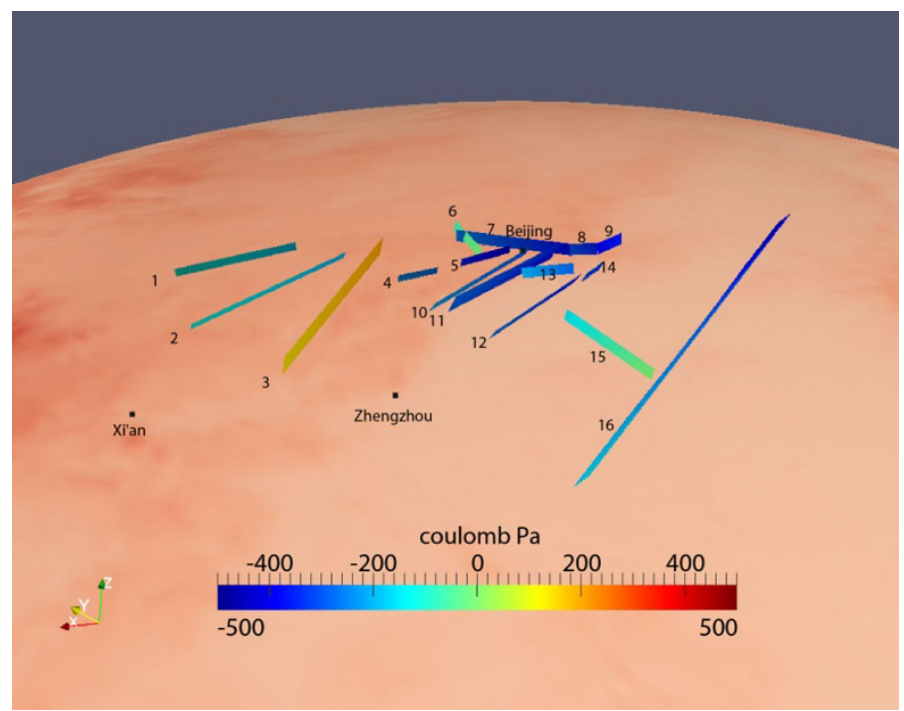

Fig. 16 Increments of coulomb stress on major faults in North China supposing the tectonic tress is NNE compressing. 1 Wulashan north, 2 Yulin-Fugu, 3 Shanxi rift, 4 Wutai mountain, 5 Weixian-Yanqing, 6 Shangyi-Huai'an, 7 Zhangjiakou-Beipiao west, 8 Zhangjiakou-Beipiao middle, 9 Zhangjiakou-Beipiao east, 10 Zijingguan, 11 north of Taihang mountain, 12 Cangdong, 13 Baodi, 14 Tangshan-Ninghe, 15 Yidu, and 16 Tanlu

stress change promotes an earthquake, while negative means obstruct an earthquake. Coulomb stress variation depends on stress change as well as strike and dip of a fault, also depends on the potential slip direction. So the effect by the same stress change could be totally different for different faults. Suppose the tectonic stress is ENE compression in North China. It is reasonable for major earthquakes in recent decades besides some exceptions. Under this assumption, we calculated $\triangle \mathrm{CFS}$ on major faults in North China (Fig. 16). It implies most faults in North China become more stable.

Through the simulation examples above, we conclude that numerical simulation could be used to study earthquake preparing, faulting, and adjustment after earthquakes. New knowledge could be got from the quantitative simulation rather than from qualitative discussion. But we cannot do earthquake prediction now because we do not know initial stress. We have to measure terrestrial stress both in shallow earth and deep Earth to promote earthquake prediction.

\section{Conclusions}

Earthquake prediction should be advanced to numerical prediction based on physical principles from the present empirical prediction based on precursors. Now it is time to make plan on how to achieve numerical prediction. There are still lots of work need to do. We have to study methods 
and theory of numerical prediction, carry out experiments, develop space geodesy research, and measure tectonic stresses. It is a long run to achieve our purpose on numerical prediction. The numerical simulation could illustrate the general patterns of earthquake preparing, faulting, and adjustment after earthquakes, but could not tell us the detail physics of earthquakes yet, even for a specific well-studied big earthquake.

Numerical prediction and empirical prediction do not reject each other. Techniques are progressing, data are accumulating, and people are introducing new theories. All of these would make the empirical prediction more accurate. Because great earthquakes are rare, so we cannot only rely on experience. In order to break through the empirical barrier, we must introduce new ideas and take new strategy. We should not only research the physics of earthquake qualitatively, but also quantitatively and develop numerical prediction. We should not talk numerical prediction in generalities, but should make tangible plans. Professionals with knowledge in geology, geophysics, and numerical simulation are needed in this area.

Numerical prediction is not an illusion but a realistic route for the future study. It took about half century to realize numerical weather forecast. It also took about half century in doing empirical earthquake prediction. How long will it take to practice numerical earthquake prediction? The task is really difficult and it is a long way to go, but we cannot be defeated by difficulties. It is the time to blow the reveille of numerical earthquake prediction now.

Acknowledgments We thank three anonymous reviewers' helpful comments. This study is supported by the CAS/CAFEA international partnership Program for creative research teams (No. KZZD-EW-TZ19) and China National Science and Technology Support Program "Practical Techniques for Earthquake Analysis and Prediction Research" 2012BAK19B03-5.

\section{References}

Allen (Chaiman) CR, Edwards W, Hall WJ, Knopoff L, Raleigh CB, Savit CH, Toksoz MN, Turner RH (1976) Predicting earthquakes: A scientific and technical evaluation-with implications for society. Panel on Earthquake Prediction of the Committee on Seismology, Assembly of Mathematical and Physical Sciences. National Research Council, U.S. National Academy of Sciences, Washington

Anonymous (1884) Weather forecasts. Science 4:568-569. doi:10. 1126/science.ns-4.99.568

Bak P, Tang C (1989) Earthquakes as a self-organized critical phenomenon. J Geophys Res (1978-2012) 94(B11):15635-15637

Bak P, Tang C, Wiesenfeld K (1987) Self-organized criticality: an explanation of 1/f noise. Phys Rev Lett 59(4):381-384

Bakun WH, McEvilly TV (1979) Earthquakes near Parkfield, California: comparing the 1934 and 1966 sequences. Science 205(4413):1375-1377

Bakun WH, Aagaard B, Dost B, Ellsworth WL, Hardebeck JL, Harris RA, Ji C, Johnston MJS, Langbein J, Lienkaemper JJ, Michael
AJ, Murray JR, Nadeau RM, Reasenberg PA, Reichle MS, Roeloffs EA, Shakal A, Simpson RW, Waldhauser F (2005) Implications for prediction and hazard assessment from the 2004 Parkfield earthquake. Nature 437(7061):969-974. doi:10.1038/ nature 04067

Barbot S, Lapusta N, Avouac JP (2012) Under the hood of the earthquake machine: toward predictive modeling of the seismic cycle. Science 336(6082):707-710. doi:10.1126/science.1218796

Barriere B, Turcotte DL (1994) Seismicity and self-organized criticality. Phys Rev E49(2):1151

Bormann P (2011) From earthquake prediction research to timevariable seismic hazard assessment applications. Pure Appl Geophys 168(1-2):329-366. doi:10.1007/s00024-010-0114-0

Chadha RK, Pandey AP, Kuempel HJ (2003) Search for earthquake precursors in well water levels in a localized seismically active area of reservoir triggered earthquakes in India. Geophys Res Lett 30(7):1416. doi:10.1029/2002GL016694

Chen YT (2008) Earthquake prediction has to overcome difficulties for advancement. Sci Technol Rev 26(10):19-21 (in Chinese with English abstract)

Chen YT (2009) Earthquake prediction: retrospect and prospect. Sci China Earth Sci 39(12):1633-1658 (in Chinese with English abstract)

Chen QF, Wang KL (2010) The 2008 Wenchuan earthquake and earthquake prediction in China. Bull Seismol Soc Am 100(5B):2840-2857. doi:10.1785/0120090314

Davis C, Keilis-Borok V, Kossobokov V, Soloviev A (2012) Advance prediction of the March 11, 2011 Great East Japan Earthquake: A missed opportunity for disaster preparedness. Int J Disaster Risk Reduct 1:17-32

Fu CY (1963) Some issues related to earthquake prediction. Chin Sci Bull 3:30-36 (in Chinese with English abstract)

Fu CY (1971) Some ideas on earthquake occurrence. Earthq Front 8:35-36 (in Chinese with English abstract)

Geller RJ (1997) Earthquake prediction: a critical review. Geophys J Int 131(3):425-450

Geller RJ (2011) Shake-up time for Japanese seismology. Nature 472(7344):407-409. doi:10.1038/nature10105

Geller RJ, Jackson DD, Kagan YY, Mulargia F (1997) Cannot earthquakes be predicted. Science 278(5337):487-490. doi:10. 1126/science.275.5306.1616

Gilbert GK (1909) Earthquake forecasts introduction. Science 29(734):121-138

Gutenberg B, Richter CF (1954) Frequency and energy of earthquakes. Seismicity of the earth and associated phenomena. Princeton University Press, Princeton, pp 17-19

Haciwara T, Rikitakk T (1967) Japanese program on earthquake prediction. A prediction program now under way in Japan succeeds in long-range forecast of the Matsushiro earthquakes. Science 157(3790):761-768

Jordan T, Chen YT, Gasparini P, Madariaga R, Main I, Marzocchi W, Papadopoulos G, Sobolev G, Yamaoka K, Zschau J (2011) ICEF Report. Operational earthquake forecasting: state of knowledge and guidelines for utilization. Ann Geophys 54(4):315-391. doi:10.4401/ag-5350

Kagan YY, Jackson DD (2000) Probabilistic forecasting of earthquakes. Geophys J Int 143(2):438-453

Kalenda P, Ouzounov D, Bobrovskiy V, Neumann L, Boborykina O, Nazarevych A, Šebela S, Kvetko J, ShenW B (2013) Multiparameter observation of pre-earthquake signals and their potential for short-term earthquake forecasting. Geophys Res Abstr 15:EGU2013-7592

Keilis-Borok V (2002) Earthquake prediction: state-of-the-art and emerging possibilities. Ann Rev Earth Planet Sci 30(1):1-33

Kerr RA (1992) Good forecast, but missed prediction. Science 258(5083):743 
Kerr RA (1993) Parkfield quakes skip a beat. Science 259(5098):1120-1122. doi:10.1126/science.259.5098.1120

Lee SP (1957) The map of seismicity of China. Acta Geophysica Sinica 6(2):127-158

Liu C, Zhu B, Shi YL (2012) Stress accumulation of the Longmenshan fault and recurrence interval of Wenchuan earthquake based on viscoelastic simulation. Acta Geol Sin 86(1):157-169 (in Chinese with English abstract)

Lorenz EN (1963) Deterministic nonperiodic flow. J Atmos Sci 20(2):130-141

Marzocchi W, Lombardi AM (2009) Real-time forecasting following a damaging earthquake. Geophys Res Lett 36(21):L21302

Marzocchi W, Zechar JD (2011) Earthquake forecasting and earthquake prediction: different approaches for obtaining the best model. Seismol Res Lett 82(3):442-448. doi:10.1785/gssrl.82.3. 442

Mei SR, Feng DY, Zhang GM, Zhu Y, Gao X, Zhang Z (1993) Introduction to earthquake prediction. Seismological Press, Beijing, p 498 (in Chinese)

Mogi K (1986) Recent earthquake prediction research in Japan. Science 233(4761):324-330

Press F (1975) Earthquake prediction. Sci Am 232(5):14-23

Press F, Brace WF (1966) Earthquake prediction. Science 152(3729):1575-1584. doi:10.1126/science.152.3729.1575

Richardson LF (1922) Weather prediction by numerical process. Cambridge University Press, Cambridge

Scholz CH, Sykes LR, Aggarwal YP (1973) Earthquake prediction: a physical basis. Science 181(4102):803-810

Shi YL (1992) Evaluation of probabilistic earthquake prediction and decision-making of releasing predictions to the public. Earthq Res China 8(2):23-28 (in Chinese with English abstract)

Shi YL (2012) Earthquake prediction: a misty dream or a realistic road. Sci Chin 11:20-27 (in Chinese with English abstract)

Shi YL, Cao JL (2008) Lithosphere effective viscosity of continental China. Earth Sci Front 15(3):82-95
Shi YL, Liu J, Zhang GM (2001) Performance of Chinese annual earthquake predictions in the nineties. J Appl Probab 38A:222-231

State Seismological Bureau of China (1982) Tangshan earthquake of 1976. Seismological Press, Beijing (in Chinese)

Uyeda S, Kamogawa M (2008) The prediction of two large earthquakes in Greece. Eos Trans Am Geophys Union 89(39):363. doi:10.1029/2008EO390002

Uyeda S, Nagao T, Kamogawa M (2009) Short-term earthquake prediction: current status of seismo-electromagnetics. Tectonophysics 470(3-4):205-213

Vere-Jones D (1995) Forecasting earthquakes and earthquake risk. Int J Forecast 11(4):503-538

Wang K, Chen QF, Sun SH, Wang AD (2006) Predicting the 1975 Haicheng earthquake. Bull Seismol Soc Am 96(3):757-795

Wei W, Sun R, Shi Y (2010) P-wave tomographic images beneath southeastern Tibet: investigating the mechanism of the 2008 Wenchuan earthquake. Sci China Earth Sci 53(9):1252-1259. doi:10.1007/s11430-010-4037-5

Wood HO, Gutenberg B (1935) Earthquake prediction. Science 82(2123):219-220. doi:10.1126/science.82.2123.219

Working Group for Re-examination of Wenchuan Earthquake Prediction, China Earthquake Administration (2009) Scientific report on Wenchuan earthquake summary and reexamination. Report of CEA (in Chinese)

Wyss M (1997) Cannot earthquakes be predicted? Science 278(5337):487-490

Zhang GM, Zhu LR, Song XD, Li ZX, Yang ML (1999) Predictions of the 1997 Strong earthquakes in Jiashi, Xinjiang, China. Bull Seismol Soc Am 89(5):1171-1183

Zhang GM, Fu ZX, Gui XT (2001) Introduction to earthquake prediction. Science Press, Beijing (in Chinese)

Zhang CJ, Shi YL, Ma L (2005) Some problems in studying slow earthquakes. J Grad Sch Chin Acad Sci 22(3):258-269 (in Chinese) 